lus trib. Año 3, n. ${ }^{\circ} 3,2017$, pp. 107-114

ISSN impreso 2518-4067 / ISSN en línea 2519-0660

doi: http://dx.doi.org/10.18259/iet.2017008

\title{
EL CONTROL DIFUSO EN SEDE ADMINISTRATIVA: UNA VISIÓN DESDE LA PERSPECTIVA DE LOS PRECEDENTES DEL TRIBUNAL CONSTITUCIONAL Y LA DOCTRINA CONSTITUCIONAL EN EL PERÚ
}

\author{
The Diffuse CONTROL IN ADMINISTRATIVE heAdqUARTERS. A VISION from \\ the Perspective of the precedents of the Constitutional Court and the \\ constitutional doctrine in Peru
}

Denisse Antezano Misajel* Universidad Continental

\section{Resumen}

En este ensayo evalúa primero las instituciones bajo las cuales se presentan los dos precedentes más resaltantes sobre el Control Difuso en Sede Administrativa, lo que conlleva entender la división de poderes del Estado Peruano y los principios de Estado Constitucional de Derecho que se encuentra íntimamente ligado al de la Supremacía Constitucional, ya que por estos se entiende que siempre se va a preferir a lo establecido en nuestra Constitución que reconoce derechos fundamentales y se rige sobre un fin supremo, que es la defensa de la persona humana y el respeto de su dignidad.

Palabras clave: Control difuso; Estado constitucional de derecho; precedente vinculante; supremacía constitucional.

\begin{abstract}
This essay evaluate the institutions that presented the two most important precedents on the diffuse Control in administrative headquarters, which implies to understand the division of powers of the Peruvian State and the principles of Constitutional state of law which is intimately linked to the constitutional supremacy, because is understood that it is always going to be preferred to what is established in our Constitution that recognizes fundamental rights and is governed by a supreme purpose, which is the defense of the human being and respect for his dignity.
\end{abstract}

Keywords: Diffuse control; Constitutional state of law; binding precedent; constitutional supremacy.

* Estudiante de Derecho en la Universidad Continental. 


\section{INTRODUCCIÓN}

En el presente ensayo académico se pretende explicar los criterios que toma el Tribunal Constitucional para que, a través de su jurisprudencia, haya determinado el uso de la figura del control difuso en la sede administrativa; asimismo, se trata de descifrar qué lleva al máximo intérprete de la Constitución a emitir después de ochos años una nueva sentencia que revoca el poder conferido a las entidades del Estado.

$\mathrm{Al}$ referirnos al control difuso, haremos referencia —en primera instanciaa su origen, que nos remonta al derecho anglosajón, concretamente al caso de Marbury vs. Madison en el año de 1803, fecha en que se instaura dicha figura jurídica. En ese orden de ideas, pretendo dar cuenta del mismo en nuestra legislación nacional que, básicamente, es un medio que tienen los magistrados del Poder Judicial para inaplicar, en un caso en concreto, una disposición legal que contravenga con la Constitución; cabe mencionar que dicha potestad también es conferida tanto a los integrantes de un tribunal arbitral como militar. Evidentemente, es necesario considerar el principio de supremacía constitucional, el cual, básicamente, postula que la Constitución va a prevalecer sobre cualquier norma inferior, lo que nos lleva a un Estado Constitucional de Derecho, en el que por cierto nos encontramos.

Entonces resulta oportuno explicar sobre la división de poderes del Estado peruano, por ende, la delegación de funciones a cada uno, para un correcto funcionamiento y en garantía del respeto a la dignidad de la persona, como refiere el artículo 1 de la Constitución, que define a ésta como su fin supremo.

Se pretende explicar también sobre la dualidad del control constitucional, que consta del control difuso y el control concentrado que recae en dos instituciones, la primera en el ya mencionado Poder Judicial, parte de uno de los poderes del Estado, y el segundo, en el Tribunal Constitucional, como un organismo constitucional autónomo.

\section{ORGANIZACIÓN DE NUESTRO ESTADO}

\subsection{La división de los poderes del Estado}

Como lo refiere la Constitución en el artículo 43, nos encontramos bajo el principio de la separación de poderes, ya que la historia nos ha demostrado que depositar todo el poder en una sola persona resulta como asevera el profesor Germán Bidart (2002, p. 224) en una tiranía y abuso. Sin embargo, 
debe acotarse que no es el poder el que se divide, se dividen sus órganos, y, por ende, sus funciones, y esta división no se realiza con el ánimo de individualizarlos, sino de balancearlos. Por ejemplo, si mencionáramos al órgano que se encarga de promover, modificar o derogar una norma, evidentemente estaríamos aludiendo al poder legislativo; mientras que si nos referimos al que ejerce el gobierno y cumple y hace cumplir con la normativa legal vigente, estaríamos dando cuenta del poder ejecutivo; por último, al mencionar al poder judicial sabemos que se centra en la administración de justicia y su llamada función jurisdiccional.

Monroy Gálvez (2009, p. 389) explica que el término jurisdicción, en general, refiere al poder genérico que un órgano del Estado, sea legislativo, jurisdiccional o administrativo, ejerce sobre un individuo.

\subsection{El Estado constitucional de derecho}

El Estado constitucional de derecho debe entenderse como que el Estado no sólo se limita a reglamentar a través de su poder competente, sino que el derecho es la condición fundamental y fin supremo. Es así que el profesor Ferrajoli explica:

Así pues, el Estado Constitucional de Derecho se configura como el instrumento constituido por el conjunto de estas normas, gracias a las cuales todos los poderes se encuentran sujetos a la ley: en el doble sentido que todos los poderes, también aquellos de mayoría, sólo pueden ejercerse en las formas establecidas por las normas formales y están, además, sujetos a normas sustanciales que imponen límites y vínculos a los contenidos de sus decisiones para tutelar los derechos de todos los individuos. (2002, p. 7)

En ese sentido, el Estado juega un rol fundamental para la mejora de la calidad de vida de sus ciudadanos, así como la garantía de que sus derechos civiles y políticos serán respetados y protegidos. Es por ello que el Estado tiene la responsabilidad de tender puentes de diálogo con los ciudadanos, para que tengan una participación activa en el crecimiento del país.

\subsection{Principio de supremacía constitucional y su nexo con el de legalidad}

$\mathrm{Al}$ encontrarnos en un Estado constitucional, este principio es una consecuencia, por este se comprende que la Constitución rige por encima de cualquier otra norma, y si una de estas contraviene lo establecido en la 
Carta Magna, podremos hacer efectivos los mecanismos de control y, por ende, hasta su expulsión del ordenamiento jurídico.

En ese sentido, podemos afirmar que el principio de legalidad tiene un nexo causal, ya que, según su interpretación, los ciudadanos no están obligados a hacer lo que la ley no demande, es decir, se le exige a los ciudadanos apegar su conducta acorde a las normativas establecidas y a su vez se protege los derechos fundamentales de los mismos en caso de que estos sean vulnerados o que exista un peligro inminente de lesión. Entonces resulta importante mencionarlos, puesto que en nuestro país el principio de legalidad se encuentra regulado también en la Ley N. 27444 , Ley del Procedimiento Administrativo General, donde se le exige a la autoridad administrativa «actuar con respeto a la Constitución, la ley y al derecho dentro de las facultades que le estén atribuidas y de acuerdo con los fines para los que les fueron conferidas.» (Numeral 1.1 del artículo IV del Título Preliminar de la Ley No 27444, Ley del Procedimiento Administrativo General).

\subsection{Control de constitucionalidad en el Perú}

En nuestro país hemos adoptado un sistema de control dual de la Constitución, en primer orden encontramos el control difuso, que tiene un origen en el derecho anglosajón, también denominado revisión judicial o judicial review, en el que se permite a los magistrados del Poder Judicial interpretar e inaplicar una ley que quebranta lo instaurado por la Constitución, pero solo en el caso concreto, exigiendo entonces en su actuar y apego al principio de supremacía constitucional señalado líneas arriba. El segundo es el control concentrado, que tiene un origen el derecho europeo, donde se congrega la facultad de interpretación de la Constitución a una sola institución que no es parte de uno de los poderes del Estado, en el caso del Perú está a cargo exclusivamente del Tribunal Constitucional, que a su vez tiene la potestad de eliminar de nuestro ordenamiento normativo la normativa que contravenga a la Constitución Política.

\section{LA JURISPRUDENCIA EMITIDA EN MATERIA DE CONTROL DIFUSO EN SEDE ADMINISTRATIVA}

Poco se ha publicado sobre este tema luego de que el Tribunal Constitucional decidiera dejar sin efecto la sentencia recaída en el expediente $\mathrm{N}$. $^{\circ}$ 
3741-2004-AA/TC, donde le otorgaba facultades a las sedes administrativas para hacer uso del control difuso. Particularmente, mostramos nuestro acuerdo con lo expuesto en la sentencia recaída en el expediente $\mathrm{N}$. $^{\circ}$ 04293-2012-PA/TC, por los argumentos que pasaremos a explicar.

Cuando se otorgan dichas facultades, se alega que no se puede hacer una interpretación positivista y formal del artículo 138 de nuestra Constitución, se alega también en el principio de unidad de la misma, ligado al de supremacía constitucional, que todo tribunal u órgano colegiado de la administración pública tiene la facultad y el deber de preferir la Constitución e inaplicar una disposición infraconstitucional que la vulnera manifiestamente, bien por la forma, bien por el fondo, de conformidad con los artículos 38, 51 y 138 de la Constitución. En ese sentido determina también que nada impide a las mencionadas instituciones a, que a través del control difuso, anular un acto administrativo inaplicando una norma legal a un caso concreto, por vulnerar los derechos fundamentales del administrado, en concordancia con la Ley del Procedimiento Administrativo General.

Tal como lo mencionaba en párrafos anteriores, el Tribunal alude al principio de legalidad, acotando que si bien nos encontramos en un Estado Constitucional de Derecho, eso no significa la simple ejecución y cumplimiento de lo determinado en las normas, sino que esto conlleva su compatibilidad con el orden objetivo de principios y valores constitucionales, haciendo un llamado a la Administración Pública para que emita sus decisiones en base a los criterios de razonabilidad, racionalidad y proporcionalidad, que también se encuentran previstos en la Ley del Procedimiento Administrativo General. Con lo mencionado, el Tribunal buscaba que no se deje de garantizar los derechos e intereses del administrado y que todo vaya con sujeción al ordenamiento constitucional (Caso Salazar Yarlenque, sentencia recaída en el expediente $\mathrm{N}^{\circ}$ 3741-2004-AA/TC).

Después de alrededor de ocho años, el Tribunal Constitucional decide revocar el precedente vinculante anterior por diversas razones que expone en su sentencia desde el fundamento 30, donde explica que la sentencia Salazar Yarlenque no contaba con los supuestos necesarios fijados en la sentencia recaída en el expediente N. ${ }^{\circ}$ 0024-2003-AI/TC, donde se establecían las reglas para fijar un precedente vinculante en materia de control difuso administrativo, puesto que no existían interpretaciones contradictorias en el tema concreto, no aclaraba ninguna interpretación errónea ni aplicación 
indebida de la norma, no existía vacío legislativo, tampoco se advierte en la práctica jurisdiccional o administrativa la existencia de interpretaciones diversas de los artículos 38, 51 y 138 de la Constitución y que en el fundamento 50 del precedente Salazar Yarlenque no se estableció para cambiar o modificar algún precedente vinculante ya existente.

Se añade también que hay justificación razonable para revocar el denominado precedente puesto que en el aspecto material existen razones suficientes para dejar sin efecto dicho precedente en base a tres razones: la primera es que la Constitución faculta el uso del control difuso a los magistrados $\mathrm{y}$ aquellos en los que recaiga la función jurisdiccional; la segunda agrega que el control difuso es un mecanismo de control constitucional al ser la sentencia elevada en consulta a la Sala Constitucional y Social de la Corte Suprema de Justicia de la República, lo que no procede en el caso de los tribunales administrativos; y la tercera porque afecta el sistema de control dual de la Constitución y el principio de división de poderes (Caso Consorcio Requena, sentencia recaída en el expediente N. ${ }^{\circ}$ 04293-2012-PA/TC).

Se debe añadir que adjunta el voto singular que realiza el magistrado Urviola Hani, quien considera no dejar sin efecto el precedente vinculante Salazar Yarlenque, puesto que el Tribunal Constitucional ha sostenido que el artículo 138 de la Constitución no puede ser interpretado de modo literal en el sentido que sólo puede ejercerlo el Poder Judicial; asimismo, el control difuso fue establecido jurisprudencialmente y no mediante una disposición constitucional expresa; el Tribunal Constitucional no puede dejar sin efecto un precedente vinculante sin analizar, previamente, cuál ha sido la utilidad o efecto que ha generado en el sistema jurídico, o si existen fórmulas para mejorarlo, y por último, los fundamentos utilizados para establecer el control difuso administrativo son los mismos que se utilizaron para establecer el control difuso arbitral.

Particularmente, considero que ambos precedentes tienen deficiencias; por un lado, el precedente Salazar Yarlenque no cumple con los requisitos para ser de carácter vinculante y el Tribunal Constitucional no considera que al otorgarles esa facultad podría no ser correctamente utilizada, ya que las personas que se encuentran a cargo de emitir ciertas resoluciones no necesariamente son conocedoras de la normativa, entonces podría existir malinterpretación de las normas y de dicha facultad que a la larga vulnere derechos fundamentales ya que no existirá un debido control sobre sus 
decisiones. Tampoco considero que sea necesario el control difuso en las sedes administrativas ya que existe un mecanismo para cuestionar aquellas normas que contravengan a la Constitución y es el proceso de inconstitucionalidad. Por otro lado, se observa que en el caso del Consorcio Requena no existía cuestionamiento alguno al control difuso en la sede administrativa, lo que podría llevarnos a aseverar que se estaría ante el principio de congruencia procesal y podría hasta surgir la interrogante de si es que el Tribunal puede hacer y deshacer en sus sentencias hasta los precedentes que no son materia de cuestión en el caso particular.

\section{CONCLUSIONES}

- Nos encontramos en una división tripartita del poder, ejecutivo, legislativo y judicial, este último está facultado para hacer uso del control difuso e inaplicar una norma para el caso concreto cuando es contraria a lo establecido por la Constitución, mientras que el control concentrado es plenamente ejercido por el Tribunal Constitucional, que tiene la potestad de expulsar una ley del marco jurídico por contravenir a la Carta Magna, mediante el proceso de inconstitucionalidad.

- Con ambas formas de control de la Constitución se pretende garantizar el principio de supremacía constitucional, en concordancia con el de legalidad, que a su vez está regulado en la Ley del Procedimiento Administrativo General.

- En el expediente Salazar Yarlenque se faculta a los órganos administrativos a ejercer el control difuso, puesto que en las entidades públicas también se presentan conflictos donde se puede encontrar normas inconstitucionales que vulneran los derechos fundamentales de los administrados y, por ende, debe existir un medio por el cual se inapliquen dichas normativas, en este caso, haciendo uso del control difuso. El Tribunal Constitucional revoca el precedente vinculante Salazar Yarlenque porque no cuenta con los requisitos y porque atenta contra la organización de nuestro Estado.

\section{BIBLIOGRAFÍA}

Bidart, G. (2002). Lecciones elementales de politica (sociedad, Estado y derecho). 2. ${ }^{2}$ ed. Lima: Grijley. 
Ferrajoli, L. (2002). Positivismo crítico, derechos y democracia. Revista Isonomía. 16. Recuperado de http://www.cervantesvirtual.com

Monroy, J. (2009). Teoría general del proceso. 3. ${ }^{a}$ ed. Lima: Communitas.

Tribunal Constitucional (2012). Caso Consorcio Requena, sentencia recaida en el expediente $N .^{\circ}$ 04293-2012-PA/TC.

Tribunal Constitucional (2004). Caso Salazar Yarlenque, sentencia recaida en el expediente $N .^{\circ} 3741-2004-A A / T C$. 